\title{
RESEARCH
}

Open Access

\section{Microglia prevent beta-amyloid plaque formation in the early stage of an Alzheimer's disease mouse model with suppression of glymphatic clearance}

Weixi Feng ${ }^{1,2}$, Yanli Zhang ${ }^{1,2}$, Ze Wang ${ }^{1,2}$, Hanrong $X u^{1,2}$, Ting $W^{3}$, Charles Marshall ${ }^{4}$, Junying Gao ${ }^{1,2^{*}}$ and Ming Xiao ${ }^{1,2^{*}}$ (D)

\begin{abstract}
Background: Soluble beta-amyloid $(A \beta)$ can be cleared from the brain through various mechanisms including enzymatic degradation, glial cell phagocytosis, transport across the blood-brain barrier, and glymphatic clearance. However, the relative contribution of each clearance system and their compensatory effects in delaying the pathological process of Alzheimer's disease (AD) are currently unknown.

Methods: Fluorescent trace, immunofluorescence, and Western blot analyses were performed to compare glymphatic clearance ability and A 3 accumulation among 3-month-old APP695/PS1-dE9 transgenic (APP/PS1) mice, wild-type mice, aquaporin 4 knock out $\left(\mathrm{AQP}^{-/-}\right.$) mice, and AQP4 ${ }^{-/-} / \mathrm{APP} / \mathrm{PS} 1$ mice. The consequence of selectively eliminating microglial cells, or downregulating apolipoprotein $E$ (apoE) expression, on A $\beta$ burden, was also investigated in the frontal cortex of AQP4 $4^{-1-} /$ APP/PS1 mice and APP/PS1 mice.

Results: AQP4 deletion in APP/PS1 mice significantly exaggerated glymphatic clearance dysfunction, and intraneuronal accumulation of $A \beta$ and apoE, although it did not lead to $A \beta$ plaque deposition. Notably, microglia, but not astrocytes, increased activation and phagocytosis of $A B$ in the cerebral cortex of AQP4 ${ }^{-1-} / A P P / P S 1$ mice, compared with APP/PS1 mice. Selectively eliminating microglia in the frontal cortex via local injection of clodronate liposomes resulted in deposition of $A \beta$ plaques in AQP4 ${ }^{-1-}$ /APP/PS1 mice, but not APP/PS1 mice. Moreover, knockdown of apoE reduced intraneuronal $A \beta$ levels in both APP/PS1 mice and AQP4 ${ }^{-1-} / A P P / P S 1$ mice, indicating an inhibitory effect of apoE on $A \beta$ clearance.

Conclusion: The above results suggest that the glymphatic system mediated $A \beta$ and apoE clearance and microglia mediated $A \beta$ degradation synergistically prevent $A \beta$ plague formation in the early stages of the AD mouse model. Protecting one or both of them might be beneficial to delaying the onset of AD.
\end{abstract}

Keywords: Alzheimer's disease, Aquaporin 4, ß-Amyloid, Glia, Glymphatic system

*Correspondence: gaojunying@njmu.edu.cn; mingx@njmu.edu.cn

'Jiangsu Province Key Laboratory of Neurodegeneration, Center for Global Health, Nanjing Medical University, Nanjing, China

Full list of author information is available at the end of the article

C The Author(s). 2020 Open Access This article is licensed under a Creative Commons Attribution 4.0 International License, which permits use, sharing, adaptation, distribution and reproduction in any medium or format, as long as you give appropriate credit to the original author(s) and the source, provide a link to the Creative Commons licence, and indicate if changes were made. The images or other third party material in this article are included in the article's Creative Commons licence, unless indicated otherwise in a credit line to the material. If material is not included in the article's Creative Commons licence and your intended use is not permitted by statutory regulation or exceeds the permitted use, you will need to obtain permission directly from the copyright holder. To view a copy of this licence, visit http://creativecommons.org/licenses/by/4.0/ The Creative Commons Public Domain Dedication waiver (http://creativecommons.org/publicdomain/zero/1.0/) applies to the data made available in this article, unless otherwise stated in a credit line to the data. 


\section{Background}

Alzheimer's disease (AD) is one of the most common neurodegenerative diseases and is partially attributed to abnormal aggregation of oligomerized beta-amyloid $(A \beta)$. Excessive accumulation of toxic forms of $A \beta$ is mainly due to an imbalance between its production and clearance [1, 2]. Failure of $A \beta$ clearance plays a crucial role in the etiology of $\mathrm{AD}$, especially sporadic AD [3-5]. Therefore, exploring mechanisms and corresponding strategies of $A \beta$ clearance will be a help in the prevention and treatment of AD.

A variety of clearance mechanisms, such as glial phagocytes, enzymatic degradation, and transport across the brain barriers, participate in the clearance of soluble brain $A \beta$ peptides [6-8]. Recently, the glymphatic system, also known as the paravascular pathway, is implicated in clearance of a major portion of extracellular $A \beta$ from the brain [9-11]. This route for $A \beta$ clearance is mainly dependent on the bulk flow of interstitial fluid (ISF), mediated by astroglial aquaporin 4 (AQP4) [1215]. AQP4, a water channel localized to perivascular end feet of astrocytes and ependymal cells, is responsible for rapid transport of water into and out of the brain parenchyma [16].

The glymphatic clearance malfunction is related to mislocalization of AQP4 due to reactive astroglosis in various mouse models, including brain aging [11], AD [17] and mild traumatic brain injury [18]. We have reported that knockout of the Aqp4 gene $\left(\mathrm{AQP} 4^{-/-}\right)$aggravates brain $\mathrm{A} \beta$ accumulation and cognitive deficits of 12-month-old APP/PS1 mice [19]. AQP4-dependent glymphatic clearance potentially serves as a therapeutic target for abnormal aggregation of macromoleculerelated neurodegenerative disorders including AD.

However, the consequences of glymphatic dysfunctions in the onset of $\mathrm{AD}$ and interactive roles of the abovementioned $A \beta$ clearance systems in delaying or retarding $\mathrm{AD}$ progress are yet to be elucidated. In the present study, we compared glymphatic clearance ability among 3-month-old AQP4 $4^{-/-} / \mathrm{APP} / \mathrm{PS} 1$ mice, APP/PS1 mice, AQP4 ${ }^{-/-}$mice, and wild-type (WT) mice. We also investigated the consequence of selectively eliminating microglial cells or downregulating apolipoprotein $\mathrm{E}$ (apoE) expression on $\mathrm{A} \beta$ burden in the frontal cortex of $\mathrm{AQP} 4^{-/-} / \mathrm{APP} / \mathrm{PS} 1$ mice and APP/PS1 mice.

\section{Methods}

\section{Animals}

APP695/PS1-dE9 transgenic (APP/PS1) mice with a C57BL/6J background were obtained from Jackson Laboratories. These mice were bred with $\mathrm{AQP} 4^{-1-}$ mice on a CD1 genetic background that were previously established in our laboratory [20]. F1 offspring were genotyped for APP and PS1 and for Aqp4 [19]. Female and male $\mathrm{AQP} 4^{+/-} / \mathrm{APP} / \mathrm{PS} 1$ mice were then mated to generate $\mathrm{F} 2$ offspring. AQP4 $4^{+/-} / \mathrm{APP} / \mathrm{PS} 1$ mice and AQP4 ${ }^{+/-}$ mice were genotyped from these F2 littermates and interbred at 3 months of age to generate $\mathrm{AQP} 4^{+/+}$(WT) mice, APP/PS1 mice, AQP4 ${ }^{-/-}$mice and AQP4 $4^{-/-} / \mathrm{APP} /$ PS1 mice. These mice were maintained until they reached 2 or 3 months of age for experiments. Animal experiments were performed in accordance with the recommendations in the Guide for the Care and Use of Laboratory Animals of Nanjing Medical University. All of the animals were handled according to approved by the Institutional Animal Care and Use Committee (NMU).

\section{Tracer injection}

Anesthetized mice were fixed to a stereotaxic frame. For intracisternal tracer injection [13], the membrane of the cisterna magna was exposed and carefully pierced by a pulled glass capillary with a $10-\mu \mathrm{m}$ tip diameter attached to a syringe. Then, $5 \mu \mathrm{l}$ of $0.5 \%$ Texas Red-dextran (TRd3, $3 \mathrm{kD}$, ThermoFisher, \#D3328) dissolved in artificial cerebrospinal fluid (CSF) was injected, at a rate of $1 \mu \mathrm{l} /$ min by a micropump (TJ-2A/L07-2A, Suzhou Wen Hao Chip Technology Co. Ltd., Jiangsu, China). For intrastriatal injection [13], the skin was opened and the skull was exposed. A burr hole was made with a hand-held drill on the coordinates: $+0.5 \mathrm{~mm}$ anterior/posterior, + $2.0 \mathrm{~mm}$ medial/lateral, and $+3.25 \mathrm{~mm}$ dorsal/ventral from bregma. The pulled glass capillary was implanted into the brain parenchyma. A $1 \mu \mathrm{l}$ volume of $0.5 \% \mathrm{TR}-\mathrm{d} 3$ was then perfused, at a rate of $0.1 \mu \mathrm{l} / \mathrm{min}$ via the micropump. The micropipette remained in place for $5 \mathrm{~min}$, then withdrew very slowly to avoid any possible backflow. Thirty minutes after intracisternal, or $1 \mathrm{~h}$ after intrastriatal injection, and with a second supplementary anesthesia, mice were transcardially perfused with fixative containing $4 \%$ paraformaldehyde (PFA) in $0.1 \mathrm{M}$ phosphate buffer. The brains and deep cervical lymph nodes (dcLNs) were removed and post-fixed for $24 \mathrm{~h}$.

\section{Cerebral injection of clodronate liposomes or adeno- associated virus (AAV) encoding apoE siRNAs}

Clodronate liposomes (Liposoma, Amsterdam, The Netherlands; \#P22JO419) were injected into the frontal cortex to deplete local microglia, as previously reported [21]. Three-month-old APP/PS1 mice and AQP4 ${ }^{-/-} /$ APP/PS1 mice were intracerebrally administrated $1.5 \mu \mathrm{l}$ clodronate liposomes, or PBS liposomes, for $5 \mathrm{~min}$ (coordinates relative to Bregma: $+1.34 \mathrm{~mm}$ anterior/posterior, $\pm 1.00 \mathrm{~mm}$ medial/lateral, and $+1.00 \mathrm{~mm}$ dorsal/ ventral). The microsyringe was withdrawn $2 \mathrm{~min}$ after injection. In order to downregulate expression of apoE in the frontal cortex, a single dose $\left(10^{10}\right.$ viral particles in $1.5 \mu \mathrm{l})$ of AAV encoding siRNAs targeting for apoE was administrated into the frontal cortex of 2-month-old 
$\mathrm{APP} / \mathrm{PS} 1$ mice or AQP4 $4^{-/-} / \mathrm{APP} / \mathrm{PS} 1$ mice with the same stereotaxic parameters mentioned above. A subgroup of $\mathrm{APP} / \mathrm{PS} 1$ mice and $\mathrm{AQP} 4^{-/-} / \mathrm{APP} / \mathrm{PS} 1$ mice received intracerebral injection of AAV encoding a non-sense sequence was used as controls. Mice were sacrificed for the $\mathrm{A} \beta$-related pathological analyses, 5 days after clodronate liposome injection or 1 month after AVV injection, respectively.

\section{Section and tissue preparation}

Following anesthesia, mice were transcardially perfused with $0.9 \%$ saline, followed by $4 \%$ paraformaldehyde (PFA) by perfusion pump (Cole-parmer, USA). Brain tissues and dcLNs were then post-fixed in 4\% PFA overnight and dehydrated in $20 \%$ sucrose solution dissolved in $0.01 \mathrm{M}$ PBS for 3 days. Sections were cut at $30 \mu \mathrm{m}$ on a cryostat (Leica, Wetzlar, Germany) and mounted onto gelatin-coated slides. For CSF tracer experiments, PFA post-fixed forebrain tissues were coronally sliced on a vibratome (Leica) at $100 \mu \mathrm{m}$ and mounted onto gelatincoated slides in sequence. For biochemical analyses, anesthetized mice were euthanized by decapitation. The cerebral cortex was promptly dissected. Tissues were flash frozen in liquid nitrogen and stored at $-80^{\circ} \mathrm{C}$ awaiting analysis.

\section{Immunofluorescence}

Brain slices were blocked for $1 \mathrm{~h}$ at room temperature with $5 \%$ BSA, incubated with primary antibodies including rabbit anti-NeuN (1:500; Abcam, \#ab177487), mouse anti-glial fibrillary acidic protein (GFAP) (1:800; Millipore, \#AB3594), rabbit anti-GFAP (1:400; Abcam, \#ab7260), rabbit anti-ionized calcium-binding adaptor molecule 1 (Iba1) (1:1000; Wako, \#019-19741), rat antiCD68 (1:100; bio-rad, \#MCA1957), goat anti-lysosomeassociated membrane glycoprotein 1 (Lamp1) (1:200, R\&D systems, \#AF4320), mouse anti-glutamine synthetase (GS) (1:100, BD, \#610517), rabbit anti-A $\beta_{1-40}$ (1: 250; CST, \#12990), mouse anti-total $\mathrm{A} \beta\left(\mathrm{A} \beta_{1-16}\right)$ (1: 1000; Covance, \# 803001), rabbit anti-AQP4 (1:400; Millipore, \#AB3594), rabbit anti-apoE (1:200; Abcam, \#ab20874), or mouse anti-apoE (1:200; Abcam, \#ab1906) overnight at $4{ }^{\circ} \mathrm{C}$. After extensive rinsing, sections were incubated for $2 \mathrm{~h}$ at room temperature with AF488conjugated donkey anti-mouse IgG (1:1000, ThermoFisher, \#A21202), AF488-conjugated donkey anti-rabbit IgG (1:1000, ThermoFisher, \#A21206), AF555conjugated donkey anti-rabbit IgG (1:1000, ThermoFisher, \#A31572), AF555-conjugated donkey anti-mouse IgG (1:1000, ThermoFisher, \#A31570), AF647conjugated donkey anti-mouse IgG (1:1000, ThermoFisher, \#A31571), or AF488-conjugated donkey anti-goat IgG (1:1000, ThermoFisher, \#A11055). The sections were washed for $3 \times 5 \mathrm{~min}$ in PBS containing $1.5 \mu \mathrm{M} \mathrm{4} 4^{\prime}$, 6-diamidino-2-phenylindole (DAPI, Invitrogen, \#D21490), then cover slipped with buffered PBS/ glycerol.

\section{Western blot}

Cerebral cortex extracts were loaded onto 10-16\% Tris/ tricine SDS gels and transferred to nitrocellulose membranes before overnight incubation with one of the following primary antibodies: mouse anti- $\beta$-site amyloid precursor protein-cleaving enzyme 1 (BACE1) (1:1000; Millipore, \#MAB5308), anti-PS1 (1:1000; Sigma-Aldrich, \#PRS4203), anti-neprilysin (NEP) (1:1000; Millipore, \#AB4348), anti-insulin-degrading enzyme (IDE) (1:1000; Abcam, \#ab32216), anti-low-density lipoprotein receptor-related protein (LRP1) (1:1000; Abcam, \#ab92544), anti-APP (C-terminal) (1:1000; SigmaAldrich, \#A8717), mouse anti-total $\mathrm{A} \beta\left(\mathrm{A} \beta_{1-16}\right)(1: 1000$; Covance, \#803001), and anti-apoE (1:1000; Abcam, \#ab20874) or GAPDH (1:1000; Bioworld; \#AP0063). Horseradish peroxidase-conjugated secondary antibodies (Vector Laboratories) were used, and bands were visualized using ECL plus detection system. GAPDH was utilized as an internal control for protein loading and transfer efficiency.

\section{Enzyme activity assay}

The enzyme activities of NEP and IDE were detected by NEP and IDE activity assay kit, respectively (ANASPEC, $\# 72223$ and \#72231). Briefly, the frontal cortex of mice was homogenized and the supernatants were collected for the following experiment. Purified NEP or IDE enzyme was used as positive control, and the fluorescence intensity was measured at $\mathrm{Ex} / \mathrm{Em}=490 \mathrm{~nm} / 520 \mathrm{~nm}$.

\section{Quantitative analyses of images}

All fluorescence micrographs were captured by a digital microscope (DM4000B, Leica) with a constant exposure time, offset, and gain for each immunofluorescent staining marker and analyzed by the Image-Pro Plus 6.0 Analysis System (Media Cybernetics Inc., San Francisco, CA, USA). The frontal cerebral cortex in each section was manually delineated. The area of positive signal of GFAP, GS, Ibal, $A \beta_{1-40}$, total-A $\beta$, thioflavine-S, or TRd3 was measured using the interest grayscale threshold analysis with constant settings for minimum and maximum intensities for each staining marker [19]. The number of total-A $\beta$ or thioflavine-S-positive plaques in the frontal cortex per section was quantified. The percentage area of positive signal was calculated by dividing the area of positive signal to the total area in the region of interest. The percentage area of TR-d3 in the dcLNs was also detected with the same method. The fluorescence intensity of TR-d3 in the cortex was determined along a corresponding linear region adjacent to the 
vessels as previously described [22]. For analysis of phagocytosis and lysosomal degradation of microglia, the percentage of area covered by double positive signal for CD68, or Lamp1, and Iba1 was calculated [14]. For analysis of total-A $\beta$ (or apoE) accumulation within neurons, astrocytes, and microglia, the percentage of area covered by double-positive signal for total-A $\beta$ (or apoE) and NeuN, GFAP, or Iba1 was calculated, respectively. The percentage of area covered by triple-positive signal for Lamp1, A $\beta$, and Iba1 was also analyzed in the images of the frontal cortex of $\mathrm{AQP} 4^{-/-} / \mathrm{APP} / \mathrm{PS} 1$ mice and APP/PS1 mice. For analysis of AQP4 polarization, the mean AQP4-immunoreactive intensity at the regions immediately abutting vessels or pia maters and correspondingly adjacent parenchymal domains was measured. AQP4 polarization was obtained by comparing expression ratios of AQP4 at perivascular or pia surface versus parenchymal domains $[9,19]$.

\section{Statistical analysis}

All data were expressed as means \pm SEM using SPSS software, version 16.0 (SPSS Inc., USA), and analyzed by Student's $t$ test or ANOVA followed by Newman-Keuls post hoc multiple comparison test as indicated in the figure legends.

\section{Results}

AQP4 deletion exacerbated impairment of glymphatic transport in 3-month-old APP/PS1 mice

Previous studies reported that glymphatic transport is suppressed in both APP/PS1 mice [17] and AQP4 ${ }^{-/-}$ mice $[9,13,15]$. In our preliminary experiments, we demonstrated that AQP4 deletion in APP/PS1 mice does not induce spatial cognitive dysfunction at 3 months old (Additional file 1: Supplemental Methods, Additional file 2: Fig. S1a-f). Therefore, this age was chosen to investigate the consequence of AQP4 deletion in APP/PS1 mice on glymphatic function by examining fluorescent tracer TR-d3 $(3 \mathrm{kDa})$ penetration into and clearance out of the brain (Fig. 1a, b). Thirty minutes after injection into the cisterna magna, parenchymal distribution of TR-d3 was less in both $\mathrm{AQP} 4^{-1-}$ mice and APP/PS1 mice than WT mice $(p<0.001 ; p<0.05$, respectively). Notably, CSF tracer influx was further decreased in $\mathrm{AQP} 4^{-/-} / \mathrm{APP} / \mathrm{PS} 1$ mice compared to that of $\mathrm{AQP} 4^{-/-}$mice $(p<0.001)$ or APP/PS1 mice $(p<0.001)$ (Fig. 1c, g). As shown by high magnification micrographs of the frontal cortex (Fig. 1d), there was strong fluorescent intensity within the perivascular space and adjacent brain parenchyma in WT mice. However, there were only weak fluorescent signals in cortical parenchyma of $\mathrm{AQP4} 4^{-/-}$mice and APP/PS1 mice. As for $\mathrm{AQP4} 4^{-/-}$/ APP/PS1 mice, the fluorescent tracer was only observed at the outermost surface of brain parenchyma.
Quantification of the TR-d3 fluorescent intensity as a function of the distance from the brain surface to the parenchyma further demonstrated that AQP4 deletion reduced glymphatic CSF influx in both WT mice and APP/PS1 mice (both $p<0.001$ ) (Fig. 1h). Consistently, AQP4 deletion also suppressed macromolecule clearance from the brain to the peripheral lymphatic system. One hour after intrastriatal injection of TR-d3, AQP4 $4^{-1-} /$ APP/PS1 mice displayed a high percentage of fluorescent areas within the striatum (Fig. 1e, i), and a low percentage of fluorescent areas within the dcLNs, compared to $\mathrm{AQP}^{-/-}$mice $(p<0.01 ; p<0.001$, respectively) or APP/ PS1 mice (both $p<0.001$ ) (Fig. 1f, j).

\section{AQP4 deficiency increased accumulation of intraneuronal $A \beta$ accumulation without causing extracellular plaque deposition in 3-month-old APP/PS1 mice}

We evaluated whether AQP4 deletion exacerbates impairments of glymphatic clearance, subsequently accelerating A $\beta$-related neuropathology of 3-month-old APP/ PS1 mice. Neither thioflavine-S-positive plaques, nor $\mathrm{A} \beta_{1-40}$ positive plaques, were visible in the cerebral cortex of APP/PS1 mice and $\mathrm{AQP} 4^{-/-} / \mathrm{APP} / \mathrm{PS} 1$ mice (Fig. 2a, b). However, AQP4 deficiency in APP/PS1 mice intensified intraneuronal $A \beta$ aggregation, as revealed by double immunofluorescent staining of NeuN and total$A \beta$ (Fig. 2c, f). Western blot results showed that the expression levels of $\mathrm{A} \beta$ monomer and oligomers were significantly increased in $\mathrm{AQP} 4^{-/-} / \mathrm{APP} / \mathrm{PS} 1$ mice $(p<$ $0.05)$, but APP and its intracellular $\beta$-C-terminal fragment (CTF- $\beta$ ) were not changed when compared with those in APP/PS1 mice (Fig. 2d, g). AQP4 deficiency did not affect expression of $\beta$-secretase, identified as BACE1, and $\gamma$-secretase, a putative enzymatic complex containing PS1, in the cortex of WT mice and APP/PS1 mice. Expression levels of LRP1, a functional protein for transport of brain $A \beta$ across the brain-blood-barrier, were also comparable among the four genotype groups. Transgenic APP/PS1 and/or AQP4 deletion did not affect protein levels of NEP or IDE, two main enzymes responsible for $A \beta$ degradation. (Fig. 2e, h). However, the enzyme activity of IDE, but not NEP, was upregulated in $\mathrm{AQP} 4^{-1-} / \mathrm{APP} / \mathrm{PS} 1$ mice, when compared that in APP/PS1 mice $(p<0.001)$ (Fig. 2i).

\section{Eliminating reactive microgliosis increased $A \beta$ aggregation in the cerebral cortex of 3-month-old AQP4 ${ }^{-/-} /$APP/PS1 mice}

Secreted IDE in the brain is mainly produced by microglia [23]. Increased IDE activity might be involved in no extracellular $A \beta$ plaque formation in 3-month-old $\mathrm{AQP4}{ }^{-/-} / \mathrm{APP} / \mathrm{PS} 1$ mice. To test this possibility, we analyzed the effect of AQP4 deletion on the activation of microglia in the early pathological stage of APP/PS1 
A

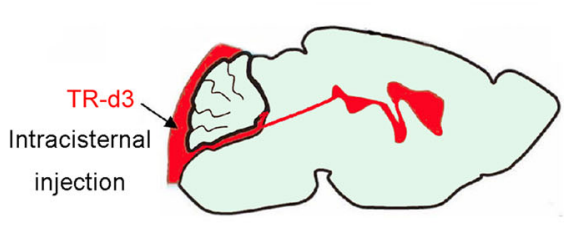

B
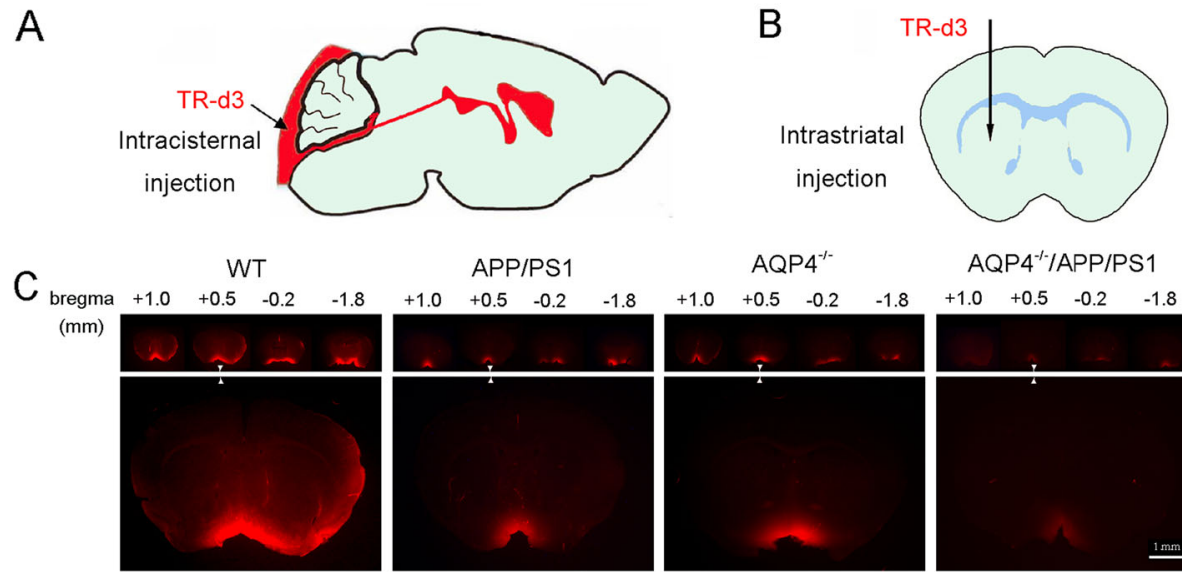

D cortex
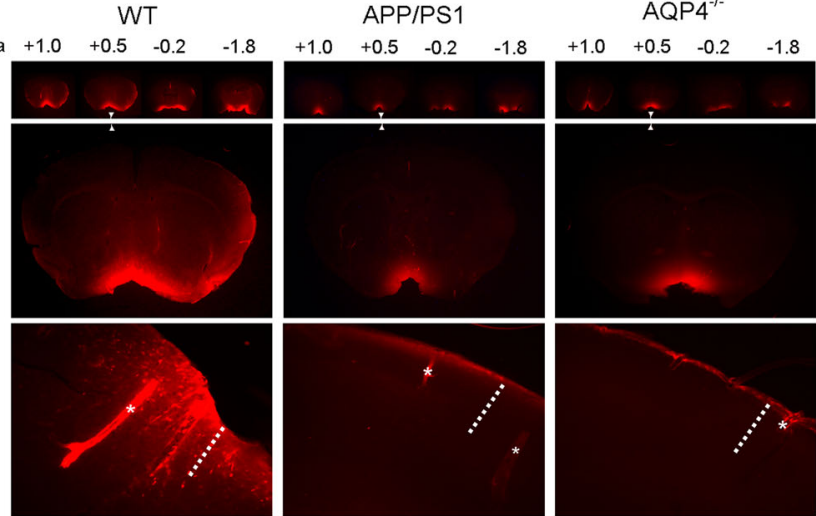

AQP4 $4^{-1 /} / A P P / P S 1$

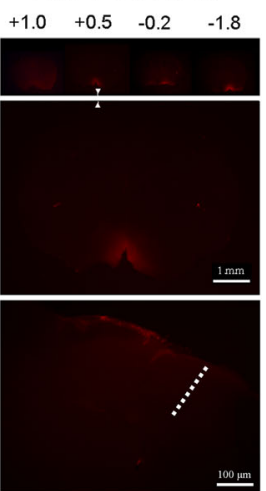

E

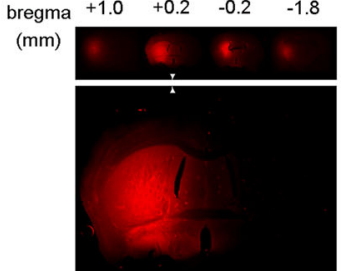

$\begin{array}{llll}+1.0 & +0.2 & -0.2 & -1.8\end{array}$
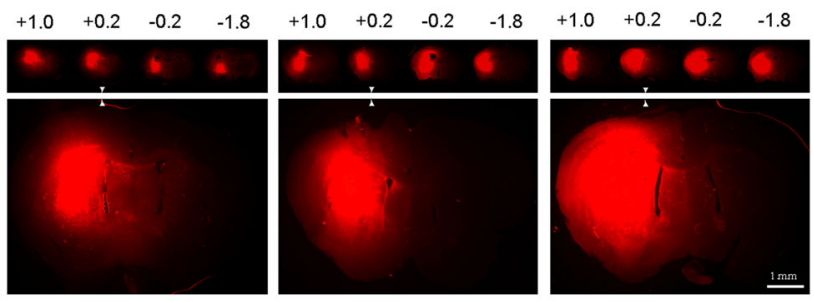

$\mathrm{F}_{\mathrm{dcLN}}$
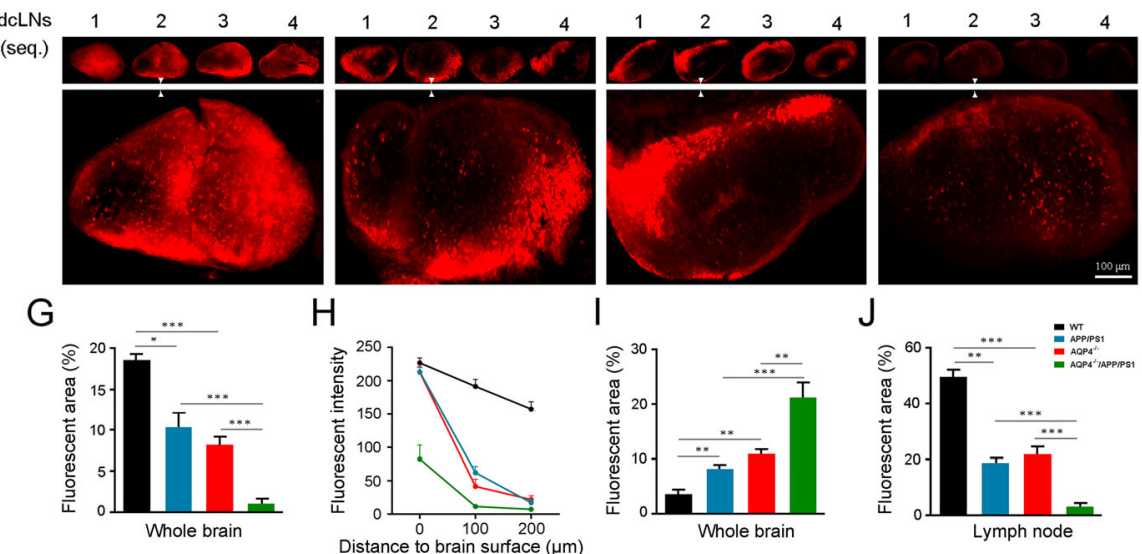

Fig. 1 AQP4 deletion aggravates decreases of florescent tracer influx into, and efflux out of, the brain of 3-month-old APP/PS1 mice. a, b Schematic images for intracisternal injection and intrastriatal injection of TR-d3. c Representative images of serial coronal brain sections from 1.0 $\mathrm{mm}$ anterior to $1.8 \mathrm{~mm}$ posterior to bregma (upper panel) and high magnification micrographs of the sections at the level of $0.5 \mathrm{~mm}$ anterior to bregma (low panel) showing TR-d3 penetration into the brain parenchyma at 30 min after intracisternal injection. $\mathbf{d}$ High magnification micrographs of the cortex showing TR-d3 penetration into the perivascular space (star) and adjacent brain parenchyma (dotted line) at 30 min after intracisternal injection. e Representative images of serial coronal brain sections from $1.0 \mathrm{~mm}$ anterior to $1.8 \mathrm{~mm}$ posterior to bregma (upper panel) and high magnification micrographs of the sections at the level of $0.2 \mathrm{~mm}$ anterior to bregma (low panel) showing residue of TR-d3 within the striatum at $1 \mathrm{~h}$ after intracisternal injection. $\mathbf{f}$ Low (upper panel) and high (low panel) magnification micrographs of sections of the dcLNs showing TR-d3 distribution at $1 \mathrm{~h}$ after intracisternal injection. $\mathbf{g}$ Quantification of intracisternally injected TR-d3 area fraction in the brain. $\mathbf{h}$ Quantification of the mean fluorescence intensity of TR-d3 in the cerebral cortex after intracisternal injection. i Quantification of intrastriatally injected TR-d3 area in the brain. $\mathbf{j}$ Quantification of intrastriatal injected TR-d3 in the dcLNs. Data were analyzed by the two-way ANOVA with Tukey's post hoc test or repeated two-way ANOVA with Tukey's post hoc test. Data are mean \pm SEM. $n=4$ per group, ${ }^{*} p<0.05 ;{ }^{* *} p<0.01 ;{ }^{* * *} p<0.001$ 


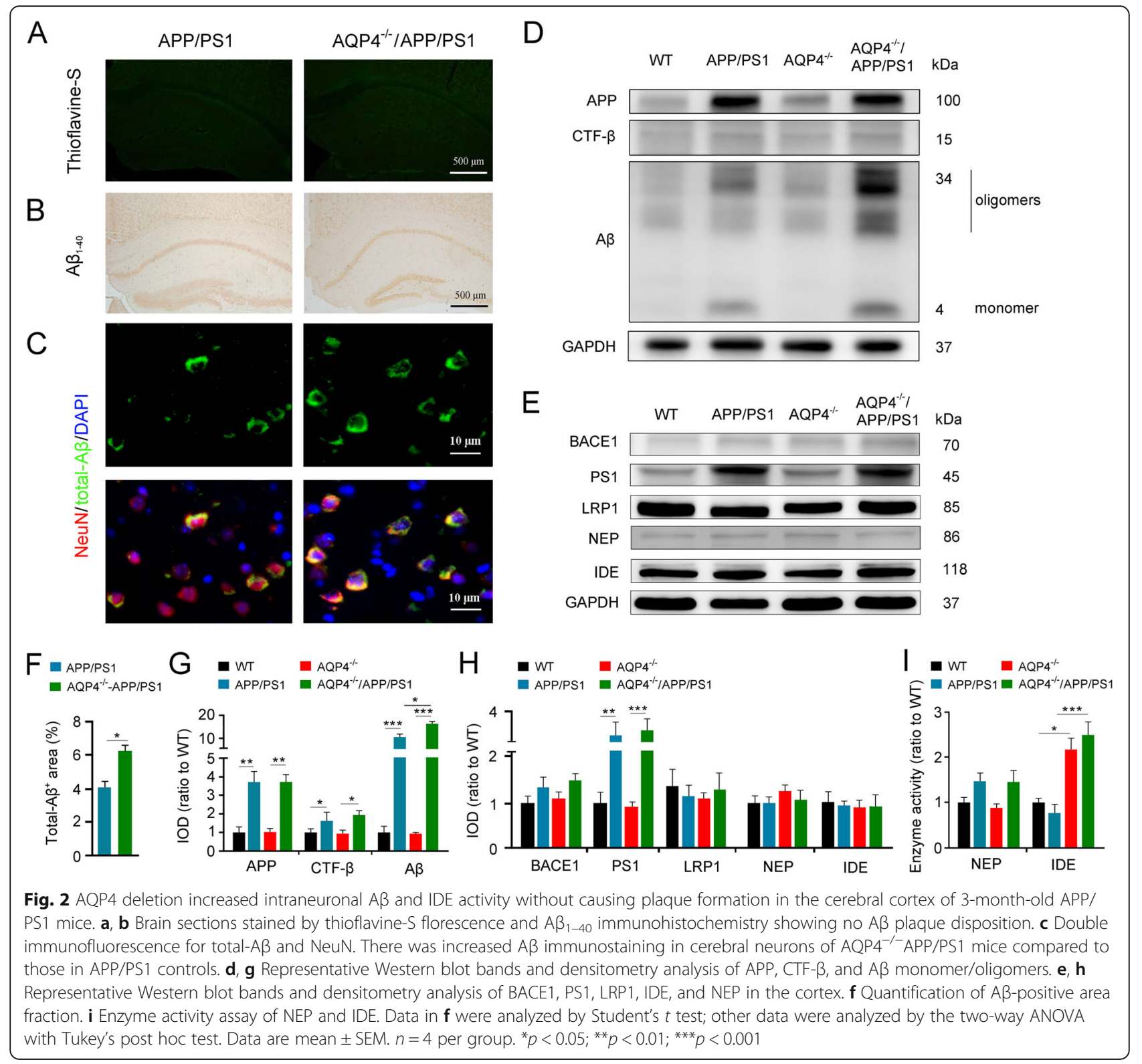

mice. AQP4 $4^{-/-} / \mathrm{APP} / \mathrm{PS} 1$ mice showed more obvious activation of microglia in the frontal cortex, as revealed by a high percentage area of Iba1 immunostaining $(p<0.05$, versus APP/PS1 mice; Fig. 3a, b). However, both $\mathrm{AQP} 4^{-/-} / \mathrm{APP} / \mathrm{PS} 1$ mice and APP/PS1 mice had mild activation of astrocytes with a similar percentage area of GFAP or GS immunopositive signals in their frontal cortex (Fig. S2a-d). Consistent with astrocyte activation, AQP4 expression was slightly but widely increased in the brain parenchyma of APP/PS1 mice, impairing its specific localization abutting microvessels and pia maters (Fig. S3a, b).

Microglia and astrocytes participate in uptake and phagocytosis of ISF $A \beta[24,25]$. We investigated the effect of AQP4 deletion on these processes in APP/PS1 mice. $\mathrm{AQP} 4^{-/-} / \mathrm{APP} / \mathrm{PS} 1$ mice exhibited more $\mathrm{A} \beta$ aggregation within the cytoplasm of Iba1-positive microglia than APP/PS1 mice $(p<0.001$; Fig. 3a, c). However, in GFAP-positive astrocytes, $\mathrm{A} \beta$ immunoreactive products were negligible in both $\mathrm{AQP} 4^{-1-} / \mathrm{APP} / \mathrm{PS} 1$ mice and APP/PS1 mice (Fig. S2a, b). These results suggest that microglia, rather than astrocytes, increase uptake of ISF $\mathrm{A} \beta$ during the early pathological stages of $\mathrm{AQP} 4^{-/-}$, APP/PS1 mice.

Microglial phagocytosis of $A \beta$ may offset impairment of glymphatic clearance of $\mathrm{A} \beta$ caused by AQP4 deletion. To test this possibility, microglia expressing CD68 and Lamp1, markers of phagocytosis and lysosomal degradation [22] were examined. AQP4 $4^{-/-} / \mathrm{APP} / \mathrm{PS} 1$ mice showed a higher percentage of area covered by CD68/ 


$$
\text { A }
$$

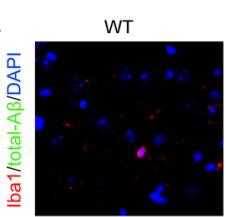

D
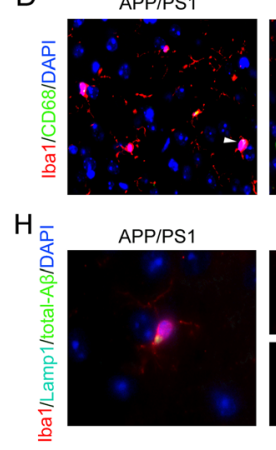

J
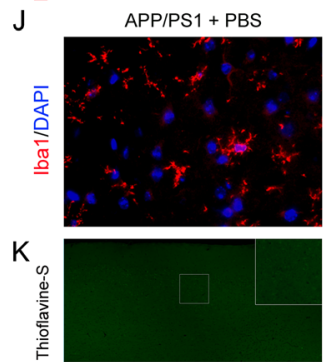

L

$L$
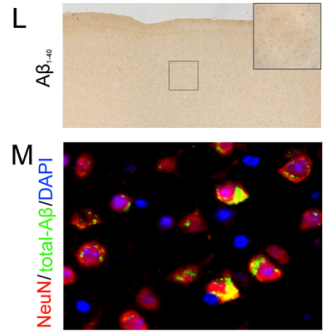

$\mathrm{N}$

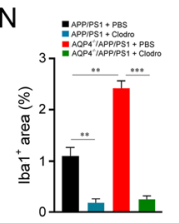

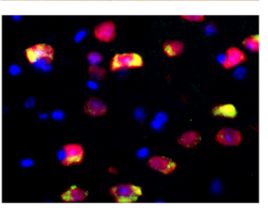

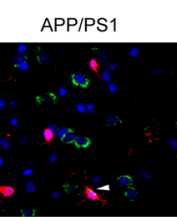

AQP4"/APP/PS1
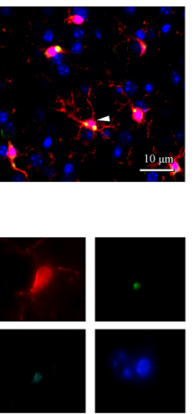

APP/PS1 + Clodro
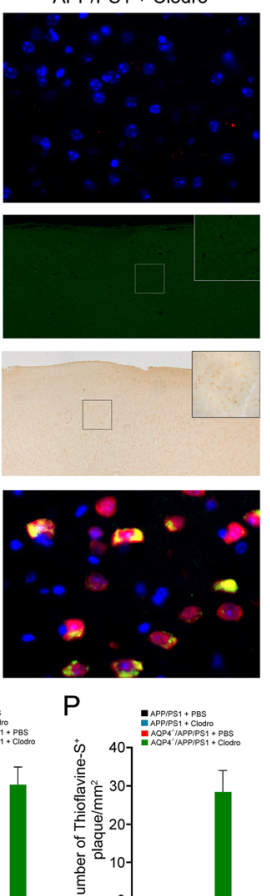
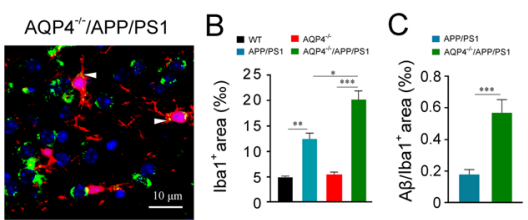

AQP4 4/APP/PS1

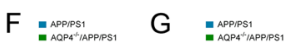
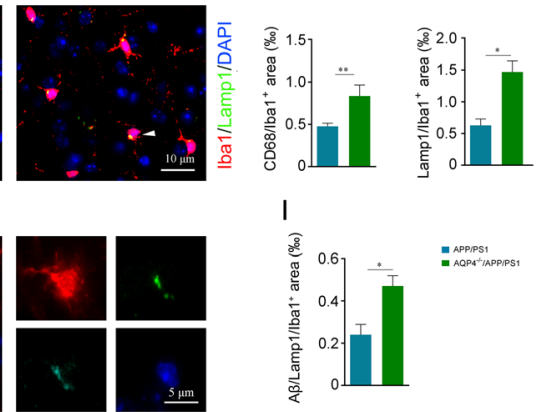

$\therefore$

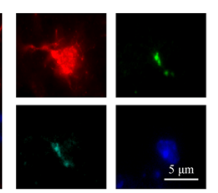

AQP4 ${ }^{-1 / A P P / P S 1}$ + PBS

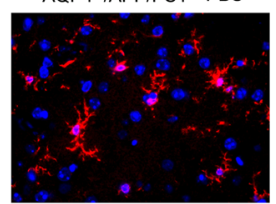

AQP4 $4^{-1} /$ APP/PS1 + Clodro
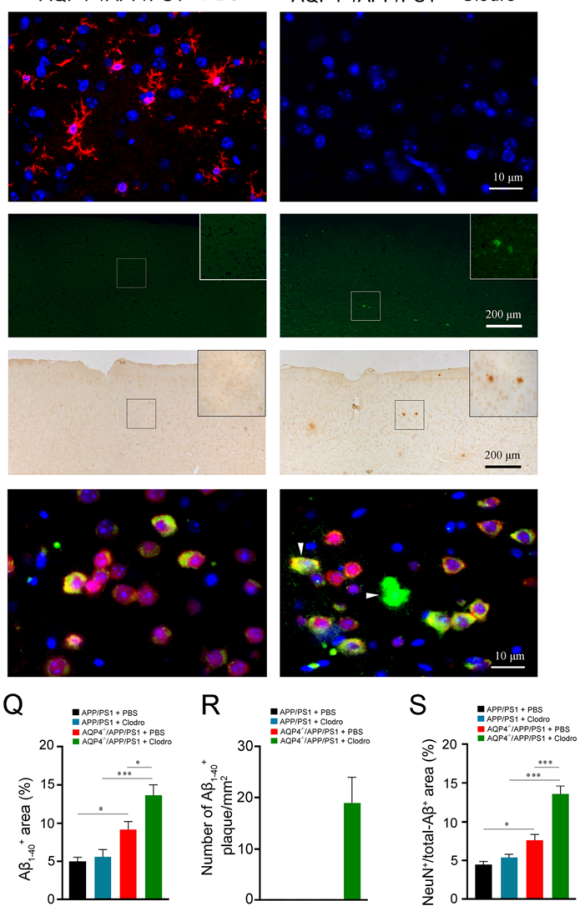

Fig. 3 Increased microglial activation, and A $\beta$ plaque deposition following eliminating microglia in AQP4 ${ }^{-/} / A P P / P S 1$ mice. a Double immunofluorescence for total-A $\beta$ and Iba1. Microglia were apparently activated in the cerebral cortex of AQP4 ${ }^{-/-} / \mathrm{APP} / \mathrm{PS} 1$ mice, compared to those in APP/PS1 controls. Dot-like signals of total-A $\beta$ (arrowheads) were frequently observed in AQP4 $4^{-/} /$APP/PS1 microglial cells. $\mathbf{b}, \mathbf{c}$ Quantification of Iba1-positive, and iba1 and total-A $\beta$ double-positive area fraction in the cerebral cortex, respectively. $\mathbf{d}$, $\mathbf{f}$ Double immunofluorescence and quantification for CD68 and Iba1. CD68-positive microglia (arrowheads) were apparently increased in the cerebral cortex of AQP4 $4^{-1} /$ APP/PS1 mice, compared to those in APP/PS1 controls. e, $\mathbf{g}$ Double immunofluorescence and quantification for Lamp1 and Iba1. Lamp1-positive microglia (arrowheads) were also apparently increased in the cerebral cortex of AQP4 $4^{-/} /$APP/PS1 mice. $\mathbf{h}, \mathbf{i}$ Triple immunofluorescence and quantification for Lamp1, total-A $\beta$, and Iba1. A immunoreactive products were restrictively localized to Lamp1-positive Iysosome of Iba1-positive microglia. $\mathbf{j}$ Iba1 positive microglia were almost eliminated in both APP/PS1 mice and AQP4 ${ }^{-/-} /$APP/PS1 with clodronate liposome treatment. $\mathbf{k}$, I Brain sections stained by thioflavine-S and $A \beta_{1-40}$, respectively. A $\beta$ plaque disposition was present at the cerebral cortex of AQP4 ${ }^{-1-}$ /APP/PS1 mice received local injection of clodronate liposomes. $\mathbf{m}$ Double immunofluorescence for total-A $\beta$ and NeuN. Total-A $\beta$ immunoreactivity (arrowheads) was increased within the cytoplasm of NeuN positive neurons of AQP4 ${ }^{-/-} / A P P / P S 1$ mice injected clodronate liposomes. $\mathbf{n}-\mathbf{s}$ Quantification of Iba1, thioflavine-S, $A \beta_{1-40}$, and total-A $\beta$-positive area fraction or number in the cerebral cortex, respectively. Data in $\mathbf{c}, \mathbf{f}, \mathbf{g}$, and $\mathbf{i}$ were analyzed by Student's $t$ test and in $\mathbf{b}, \mathbf{n}, \mathbf{q}$, and $\mathbf{s}$ were analyzed by the two-way ANOVA with NewmanKeuls post hoc test. Data are mean \pm SEM, $n=4$ per group, ${ }^{*} p<0.05 ;{ }^{* *} p<0.01 ;{ }^{* * *} p<0.001$ 
Iba1 or Lamp1/Iba1 double-positive signals in the frontal cortex than APP/PS1 mice $(p<0.01, p<0.05$, respectively; Fig. $3 \mathrm{~d}-\mathrm{g})$. Moreover, Lamp1/A $\beta / \mathrm{Iba1}$ triple immunostaining revealed that $\mathrm{A} \beta$ in the lysosome of microglia was also increased in $\mathrm{AQP} 4^{-/-} / \mathrm{APP} / \mathrm{PS} 1$ mice $(p<0.05$; Fig. $3 \mathrm{~h}, \mathrm{i})$, indicating increased phagocytic ability of $\mathrm{A} \beta$ by activated microglia.

To verify this speculation, clodronate liposomes, which specifically depletes macrophages [20, 26, 27], were injected into the frontal cortex to locally eliminate microglia (Fig. 3j, n). Both thioflavine-S-positive plaques and $A \beta_{1-40}$-positive plaques were clearly observed in the frontal cortex of $\mathrm{AQP} 4^{-/-} / \mathrm{APP} / \mathrm{PS} 1$ mice, but not APP/ PS1 mice, 5 days after treatment of clodronate liposomes (Fig. 3k, l, o-r). AQP4 $4^{-/} / \mathrm{APP} / \mathrm{PS} 1$ mice injected with clodronate liposomes also noticeably improved accumulation of intracellular A $\beta(p<0.001$, versus PBS controls; Fig. $3 \mathrm{~m}, \mathrm{~s})$. In addition, astrocytes in the frontal cortex underwent elevated activation in both APP/PS1 mice and $\mathrm{AQP} 4^{-/-} / \mathrm{APP} / \mathrm{PS} 1$ mice that received injection of clodronate liposomes (Fig. S4a, b).

\section{Increased apoE levels in the brain of 3-month-old $\mathrm{AQP}^{-/-} / \mathrm{APP} / \mathrm{PS} 1$ mice}

ApoE, a cholesterol transport protein, also regulates $A \beta$ metabolism, aggregation, and deposition [28]. A previous study reported that the glymphatic system mediates apoE transport within the brain [29]. Therefore, we investigated whether AQP4 deletion affects apoE levels in the brain of 3-month-old APP/PS1 mice. Western blot analysis showed that AQP4 deletion in either WT or APP/PS1 mice resulted in high levels of apoE in the cerebral cortex $(p<0.05, p<0.001$, respectively; Fig. 4a, b). We further identified localization of apoE within different types of brain cells. Immunofluorescence revealed that the immunoreactive products of apoE in WT mice were localized within the cytoplasm of a small portion of astrocytes (Fig. 4c) and neurons (Fig. 4d). AQP4 deletion in APP/PS1 mice led to increased apoE in astrocytes as well as neurons (Fig. 4c, d, f-h). This result is in agreement with the view that apoE is generated mainly by glial cells, whereas neurons predominantly produce apoE under stressful conditions [30,31]. Notably, there was a high cellular co-localization of apoE and total-A $\beta$ in $\mathrm{AQP} 4^{-/-} / \mathrm{APP} / \mathrm{PS} 1$ mice, compared with APP/PS1 mice $(p<0.001$; Fig. 4e, i). This supports that there is a high affinity between apoE and $A \beta$, which will facilitate the formation of apoE/A $\beta$ complexes [31-33].

\section{Knockdown of apoE reduced intraneuronal aggregation of $A \beta$ in the brain of 3-month-old APP/PS1 mice with or without AQP4 deletion}

We further determined the effect of downregulating on intraneuronal $A \beta$ load by injection of AAV encoding
siRNAs targeting apoE into the frontal cortex (Fig. S5ad). The apoE levels dramatically decreased in 3-monthold APP/PS1 mice and AQP4 $4^{-/-} / \mathrm{APP} / \mathrm{PS} 1$ mice that had been pre-injected with the above AAV a month earlier, as revealed by Western blot (Fig. 5a, b) and immunostaining (Fig. 5c, d). As expectedly, local knockdown of apoE decreased intraneuronal accumulation of $A \beta$ in both APP/PS1 mice and AQP4 $4^{-/-} / \mathrm{APP} / \mathrm{PS} 1$ mice (both $p<0.001$; Fig. $5 \mathrm{e}-\mathrm{g}$ ). In addition, Western blot results showed that administration of AAV encoding siRNAs targeting apoE significantly decreased the level of $A \beta$ $(p<0.05$; Fig. $5 \mathrm{~h}, \mathrm{i})$, without altering APP and CTF- $\beta$ levels (Fig. 5h, i). These data indicate that dysfunction of the glymphatic system mediated apoE clearance is a main contributor to intraneuronal accumulation of $A \beta$ in the early pathological stages of AD.

\section{Discussion}

It is widely accepted that an age-related decline in $A \beta$ clearance is central to the onset of $\mathrm{AD}$, although exact pathogenesis of the disease remains elusive $[1,2]$. APP/ PS1 mice serve as the most extensively used mouse model of $\mathrm{AD}[34,35]$. This mouse line exhibits extracellular $A \beta$ deposition until 5-6 months old, mainly attributed to the decompensation of clearance ability under long-term high levels of $A \beta$ burden [36, 37]. Therefore, we chose the 3 -month-old time point to characterize the profile of $A \beta$ clearance related markers in the early stage of this $\mathrm{AD}$ mouse model (Fig. 6). We further observed the consequences of whole body knockout of the Aqp4 gene, local microglia elimination, and knockdown of the apoE gene on $A \beta$ load within neurons and extracellular space of the frontal cortex, respectively.

Evidence from recent studies has highlighted that the glymphatic system plays a dominant role in the clearance of ISF $A \beta$ [9-11], and its malfunction may be an aggravating factor in brain aging and $\mathrm{AD}[11,12,38]$. The present study has demonstrated that glymphatic transport of a CSF tracer is suppressed in the 3-monthold APP/PS1 brain prior to A $\beta$ plaque deposit. This supports the view that glymphatic dysfunction potentially serves as an early pathological marker of AD [17]. Glymphatic impairment could be associated with mislocalization of AQP4 due to astrocyte activation [10-15]. In addition, previous studies suggested that soluble $A \beta$ peptides, especially $A \beta_{1-40}$, directly inhibit glymphatic transport [17]. However, it remains to be determined which mechanism plays the leading role in suppressing glymphatic function during the early stage of AD.

Evidence from several independent groups has revealed AQP4-dependent glymphatic solute transport in the rodent brain $[9,13,15]$, despite others reporting conflicting results [39, 40]. The present study further confirms the importance of AQP4 in glymphatic 


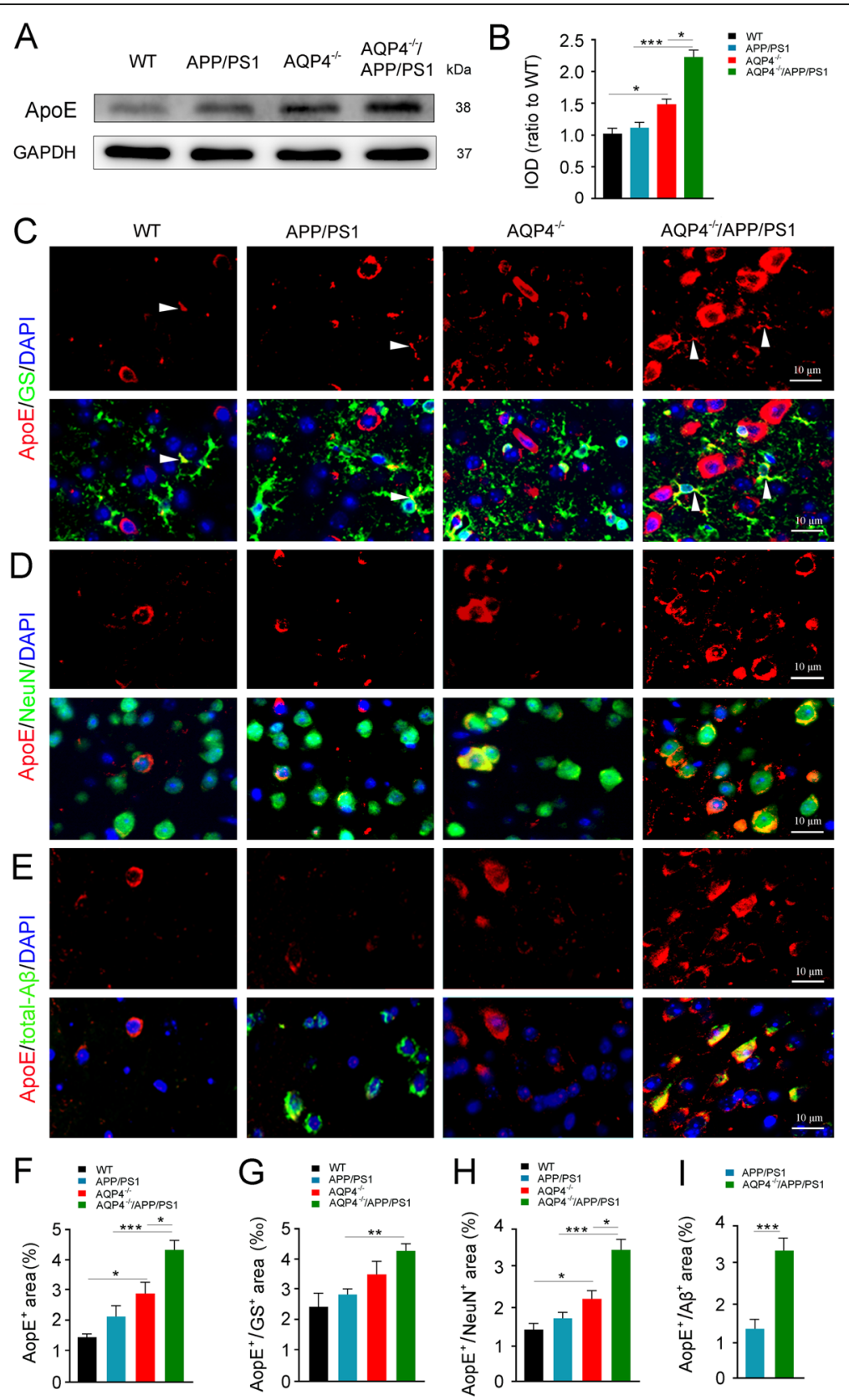

Fig. 4 AQP4 deletion increased intraneuronal apoE aggregation in 3-month-old AQP4 ${ }^{-/-} / A P P / P S 1$ mice. $\mathbf{a}$, b Representative bands of Western blot and densitometry analysis of apoE. c-e Double immunofluorescence of apoE/GS, apoE/NeuN, and apoE/total-A , respectively. Note that AQP4 deletion in APP/PS1 mice increased apoE immunoreactive intensity in GS-positive astrocytes and NeuN-positive neurons. ApoE and total-A $\beta$ double immunoreactive products were also accumulated. $\mathbf{f}-\mathbf{i}$ Quantification of apoE, apoE/GS, apoE/NeuN, and apoE/total-A - -positive area fraction in the cerebral cortex, respectively. Data in i were analyzed by Student's $t$ test; other data were analyzed by the two-way ANOVA with Newman-Keuls post hoc test. Data are mean \pm SEM, $n=4$ per group, ${ }^{*} p<0.05 ;{ }^{* *} p<0.01 ;{ }^{* * *} p<0.001$

clearance. Both CSF tracer influx and ISF tracer efflux are decreased following the Aqp4 gene knockout with or without transgenic APP/PS1. Notably, AQP4 deletion dramatically reduces the transport rate of intrastriatal TR-d3 into the dcLNs. This result further emphasizes that AQP4-mediated rapid water transport is involved in glymphatic macromolecule drainage from the brain into the peripheral lymphatic system.

The current results have revealed that $A \beta$ is aggregated within frontal cortex neurons of APP/PS1 mice at 3 months old, compared to WT controls, but has yet to cause obvious $A \beta$ plaque formation. The absence of 


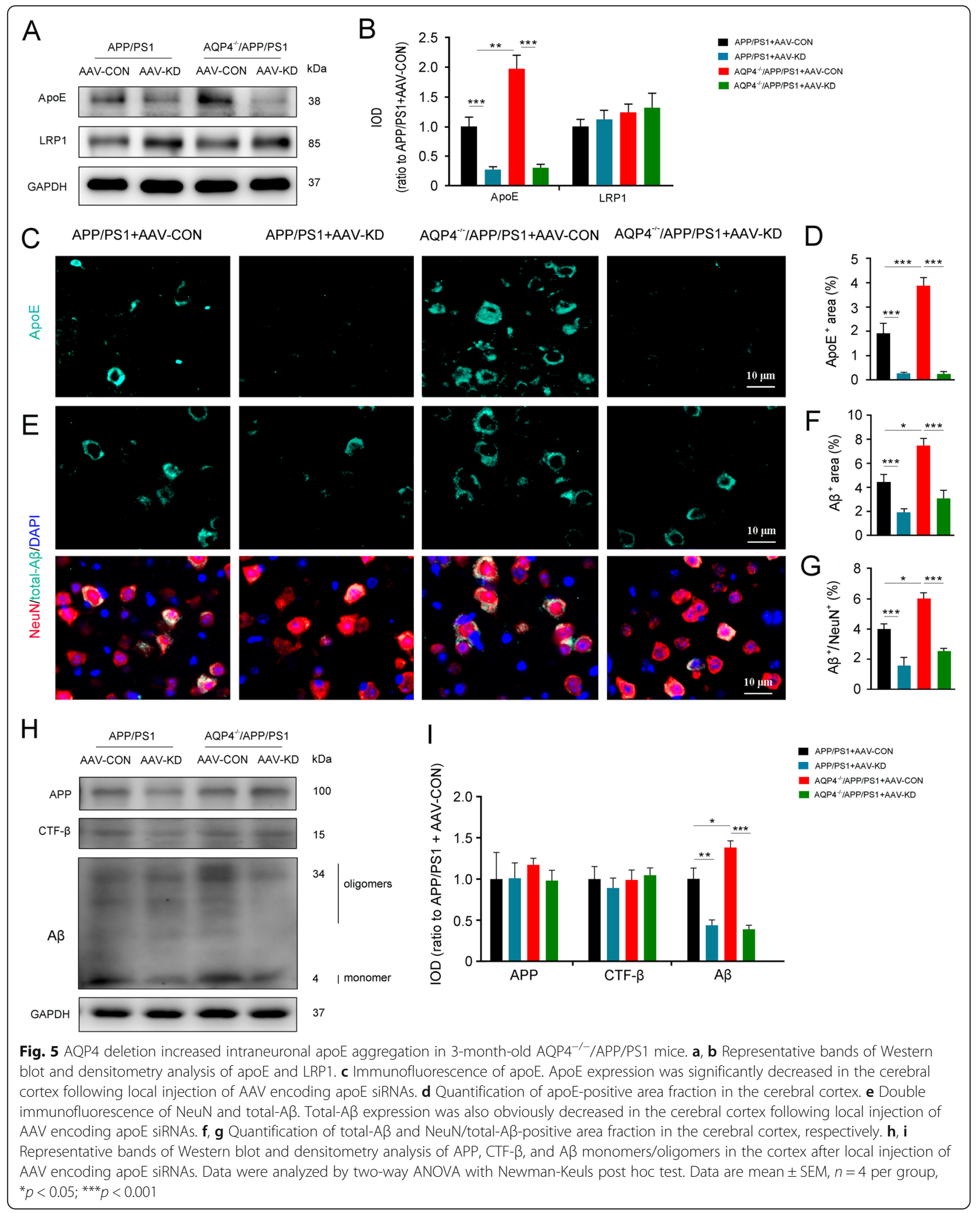




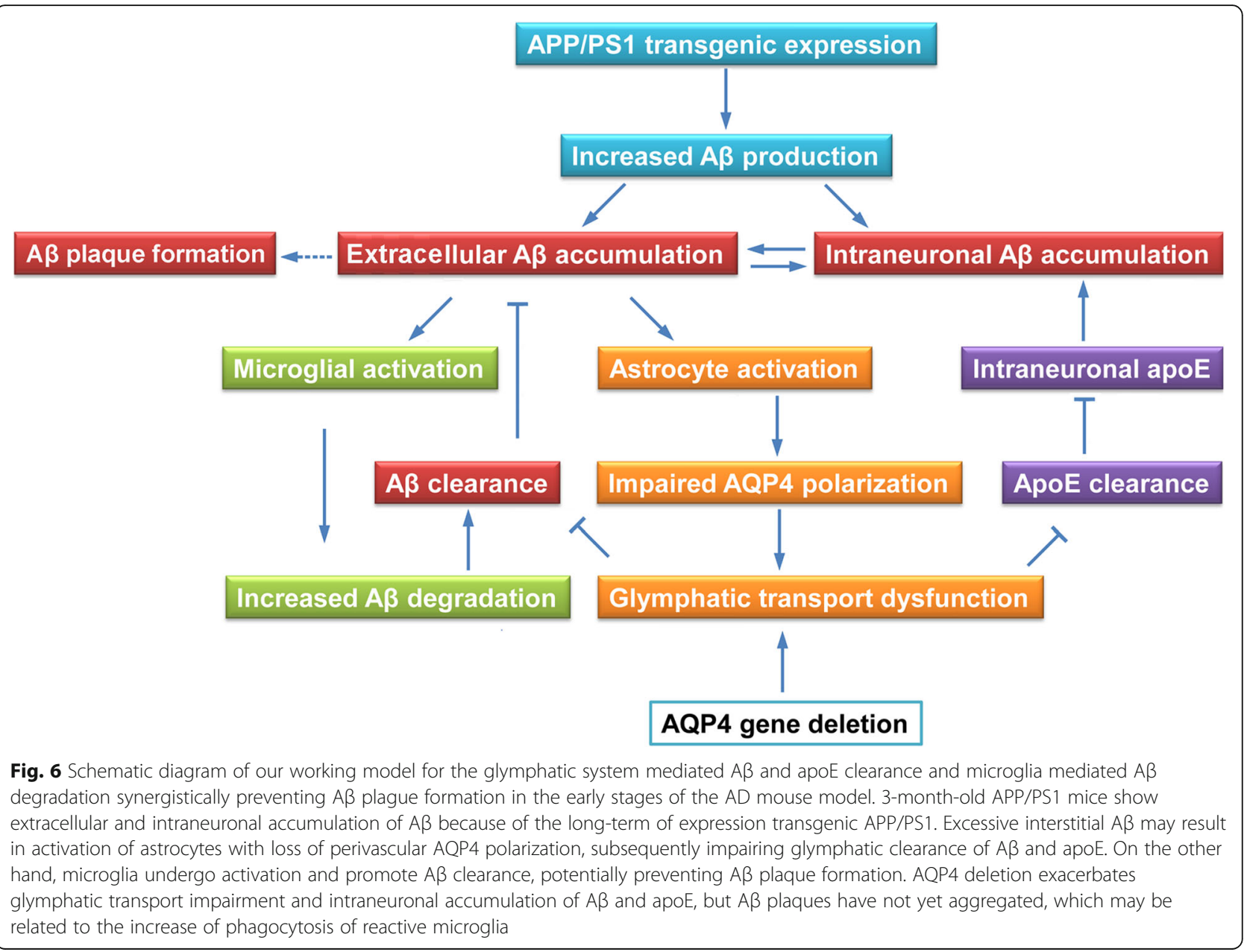

AQP4 does not cause $A \beta$ plaque formation, but rather exacerbates intraneuronal $A \beta$ aggregation in the early stage of this $\mathrm{AD}$ mouse model. This result supports the view that build-up of $A \beta$ within neurons may play a crucial role in plaque formation [41-43].

The following compensatory mechanisms related $A \beta$ clearance might contribute to no $A \beta$ plaque formation despite an intensified glymphatic clearance dysfunction caused by AQP4 deletion. First, there is normal expression level of LRP1, which is responsible for transfer of $A \beta$ outside the brain [6, 7]. Second, dural lymphatic drainage remains intact. Recent studies have shown that brain interstitial fluid and macromolecules can be transported into the dcLNs through meningeal lymphatics [44-46]. Our previous studies have also suggested that the extra cranial brain clearance pathway remains intact in 6-month-old APP/PS1 mice, but the deposition of A $\beta$ plaques significantly increases after the mice received bilateral ligation of afferent vessels of the dcLNs [47]. More importantly, clearance of $A \beta$ may be improved by activation of microglia $[24,25]$. In the present study, $A \beta-$ positive products, and $\mathrm{CD} 68$, a phagocyte-associated marker [22], are detected in cell bodies of activated microglia in the frontal cortex of $\mathrm{AQP} 4^{-/-} / \mathrm{APP} / \mathrm{PS} 1$ mice. Furthermore, Lamp1/A $\beta /$ Iba1 triple immunostaining has revealed that a considerable portion of $A \beta$ positive products are located within lysosomes of $\mathrm{AQP}^{-/-} / \mathrm{APP} / \mathrm{PS} 1$ microglia. In addition, there was increased activity of IDE, mainly produced by microglia within the brain [23], in the cerebral cortex of $\mathrm{AQP}^{-1-}$ / APP/PS1 mice. Together, these results indicate that microglial phagocytosis and enzymatic degradation are potentially beneficial to prevent accumulation of extracellular $A \beta$. Indeed, clodronate liposomes that eliminates microglia for only 5 days cause $A \beta$ plaque deposition in the frontal cortex of 3 -month-old $\mathrm{AQP} 4^{-/-} / \mathrm{APP} / \mathrm{PS} 1$ mice.

Interestingly, eliminating microglia does not enhance $\mathrm{A} \beta$ plaque formation in 3-month-old APP/PS1 mice, which could be attributed to an alleviated impairment of glymphatic transport compared to that in $\mathrm{AQP4}^{-/-} /$ APP/PS1 mice with the same age. In addition, we have discovered a significant reduction of LRP1, and more severe $A \beta$ plaque deposition, in the brain parenchyma and 
vascular amyloidosis of 12-month-old $\mathrm{AQP} 4^{-/-} / \mathrm{APP} /$ PS1 mice, compared with their APP/PS1 littermates [19]. These results suggest that glial cell phagocytosis, enzymatic degradation, glymphatic clearance, and LRP1mediated transport working together prevent $A \beta$ plaque formation. However, the compensatory roles of these $A \beta$ clearance systems are gradually diminished, resulting in extracellular $A \beta$ aggregation with pathological progression of AD.

Our experimental results have illustrated that the absence of AQP4 does not increase reactive astroglosis in cerebral cortex of 3-month-old APP/PS1 mice, which is contrary to results found in microglia. Our previous study demonstrated that 6-month $\mathrm{AQP}^{-1-} /$ APP/PS1 mice have more extensive reactive gliosis than APP/PS1 mice, and at 12 months a large number of astrocytes around $A \beta$ plaques undergo atrophy [19]. An early study from our laboratory has reported that AQP4 deficiency decreases $A \beta$ uptake in cultured astrocytes, and in turn attenuates changes in mitogenactivated protein kinase pathways, finally reducing astrocyte activity [48]. Similarly, reduced reactive astroglosis is likewise observed in 7-9-month-old AQP4 ${ }^{-/} / 5 x$ Tg-AD mouse brains [49]. These data together indicate that long-term loss of AQP4 not only damages glymphatic clearance of $A \beta$, but also decreases astrocyte phagocytosis of $A \beta$, in turn exacerbating the pathological progression of $\mathrm{AD}$.

ApoE, a lipid carrier protein, is produced by astrocytes and secreted as high-density lipoprotein-like particles in the brain. ApoE can directly bind to $A \beta$ amino-acid residues [12-28], subsequently forming apoE/A $\beta$ complex within neurons and extracellular space [31-33]. Co-deposition of apoE with $A \beta$ is a key step for $A \beta$ fibrillization and plaque formation $[50,51]$. Therefore, blocking apoE/A $\beta$ interaction may be a promising strategy for improving clearance of soluble $A \beta$ from the brain, and preventing the onset of AD. However, there is still lack of safe and effective routes to inhibit apoE aggregation within the brain parenchyma. The current study has revealed $A \beta$ and apoE co-accumulation within neurons prior to plague formation in 3-month-old APP/PS1 mice. A recent study has reported that the glymphatic system contributes to the delivery of CSF-derived apoE to neurons. CSF apoE distribution in brain is reduced in $\mathrm{AQP} 4^{-/-}$mice [17]. Consistently, we have shown that $A Q P 4$ deletion increases $A \beta$ and apoE co-aggregation within neurons, supporting that glymphatic dysfunction is an important factor in $\mathrm{A} \beta$ pathogenesis. Moreover, the current results suggest that knockdown of apoE expression significantly attenuates intraneuronal aggregation of $A \beta$. This is consistent with findings reporting the mitigating effects of apoE knock-out on fibrillar $A \beta$ deposits and neurodegeneration in several AD-Tg mouse models [52-55].

In addition, accumulated evidence has highlighted that inheritance of the APOE $\varepsilon 4$ allele is the strongest known risk factor for sporadic $\mathrm{AD}[56,57]$. A previous study has indicated that both apoE2, apoE3, and apoE4 isoforms contribute to $A \beta$ deposition in APP/PS1 mice [58]. A recent study has revealed that apoE secreted by glia stimulates neuronal $A \beta$ production with an ApoE4 $>$ ApoE3 $>$ ApoE2 potency rank order [59]. Further study is necessary to identify which subtype apoE is affected by glymphatic dysfunction in this AD model, due to the fact that a facilitating effect of glymphatic transport of CSFderived apoE is in an isoform-specific manner (apoE2 $>$ apoE3 $>$ apoE4) [17]. It is necessary to further determine whether increased ApoE production is also involved in accumulation of apoE in the brain after deletion of AQP4. Exploring this issue is helpful to reveal the interaction between AQP4 and apoE in the pathogenesis of $\mathrm{AD}$.

Apart from $A \beta$, evidence from recent studies suggests that apoE influencing tau pathology and tau-mediated neurodegeneration is also in an isoform-dependent manner [60, 61]. Furthermore, apoE $\varepsilon 4$ accumulation impairs glial responsiveness, lipid transport, and cerebrovascular integrity and function, which might be independent of $A \beta$-related pathways $[31,62,63]$. These results indicate that promoting glymphatic clearance of macromolecular metabolic proteins including $A \beta$, Tau, and apoE may counteract pathological cascades of $\mathrm{AD}$ in multiple aspects, potentially delaying the onset and development of the disease.

\section{Conclusion}

The present study has characterized pathological features of $\mathrm{A} \beta$ clearance systems of 3-month-old APP/ PS1 mice. AQP4 deletion exacerbates glymphatic clearance impairment with increases in intracellular accumulation of $\mathrm{A} \beta$ and apoE in APP/PS1 brain. Furthermore, it also improves IDE activity and microglia phagocytosis without aggravating $A \beta$ plaque deposition and spatial cognitive dysfunction. Eliminating microglial cells causes $A \beta$ deposition in the brain of $\mathrm{AQP} 4^{-/-} / \mathrm{APP} / \mathrm{PS} 1$ mice, but not APP/PS1 mice. Knockdown of apoE reduce intraneuronal $A \beta$ levels in APP/PS1 mice with or without AQP4. These results have preliminarily revealed an interactive compensation between glymphatic clearance and microglial phagocytosis in inhibiting brain $A \beta$ accumulation in the early stage of AD-like progression. This might provide a promising strategy for preventing the onset of $\mathrm{AD}$. 


\section{Supplementary information}

Supplementary information accompanies this paper at https://doi.org/10. 1186/s13195-020-00688-1.

Additional file 1. Morris water maze. The Morris water maze test was conducted to measure mouse long-term spatial cognitive function, as described previously [19]. Four Training was performed over 7 consecutive days, with 4 trials per day. During the first two days, mice were trained to find a dark-colored cylindrical platform with a diameter of $10 \mathrm{~cm}$, sitting $0.5 \mathrm{~cm}$ above the water surface. Mice did not receive the next hidden platform tests if they had apparent motor and/or visual deficits indicated by low swimming speed ( $<75 \mathrm{~mm} / \mathrm{s}$ ) or long escape latency ( $>50 \mathrm{~s})$. On the $3 \mathrm{rd}$ day, the platform was submerged $1 \mathrm{~cm}$ below the surface of the water and moved to the opposite quadrant. Escape latency, swimming distance and swimming speed were calculated. On day 8 , the hidden platform was removed, allowing mice to swim freely in the pool for $60 \mathrm{~s}$. The percentage of time spent in the target quadrant and the number of crossing where the platform had been previously located were analyzed. Y-maze test. The Y-maze test was performed to evaluate mouse shortterm spatial working memory, as previously described [19]. One arm, termed the novel arm, was blocked by a black baffle, allowing the mice to only move in the other two arms for $5 \mathrm{~min}$. Two hours later, the novel arm was opened, allowing mice to freely move throughout the three arms. The percentage of time traveled in, number of entries into the novel arm, as well as traveling speed during the test, was calculated. Mouse activity in the aforementioned behavioral apparatuses was collected by a digital video camera connected to a computer-controlled system (Beijing Sunny Instruments Co. Ltd., China). All tests were performed by two independent experimenters, who were each blind to the treatment schedule.

Additional file 2: Fig. S1. No obvious effects of AQP4 deletion on spatial cognitive function of 3-month-old APP/PS1 mice. $a, b$ The mean escape latency and swimming speed during the training period of the Morris water maze test. c The number of crossing the platform. $d$ The percentage of time in the target quadrant. e The number of entries into the novel arm. $f$ The percentage of time in the novel arm in the Y-maze. Data in S1a, b were analyzed by repeated-measures ANOVA with post hoc Student-Newman-Keuls test. Other Data were analyzed by ANOVA with post hoc Student Newman-Keuls test. Data are means \pm SEM. $n=12$ per group. Fig. S2. AQP4 deletion did not affect astrocyte activation in 3-month-old APP/PS1 mice. a, b Double immunofluorescence and quantification for GFAP and total-A $\beta$ in the cortex. $c$, $d$ Immunofluorescence and quantification for GS positive astrocytes in the cortex of APP/PS1 mice and $\mathrm{AQP} 4^{-/-} / \mathrm{APP} / \mathrm{PS} 1$ mice. Data are means \pm SEM. $n=4$ per group, two-way ANOVA with Newman-Keuls post-hoc test. Fig. S3. AQP4 polarization was impaired in the cerebral cortex of 3-month-old APP/PS1 mice. a Double immunofluorescence for AQP4 and GFAP. b Quantitative analyses of the AQP4 polarization. Data are means \pm SEM. $\mathrm{n}=4$ per group, Student's t-test. ${ }^{* *} p<0.01 ;{ }^{* * *} p<0.001$. Fig. S4. Increased astrocyte activation in the cortex in 3-month-old APP/PS1 mice and $\mathrm{AQP} 4^{-1} / \mathrm{APP} / \mathrm{PS} 1$ mice receiving local injection of clodronate liposomes. $a, b$ Double immunofluorescence and quantification for total-A $\beta$ and GFAP in the cortex. Data are means \pm SEM. $n=4$ per group, twoway ANOVA with Newman-Keuls post-hoc test. Fig. S5. An image shows GFP expression in the cortex one month after injection of AAV encoding apoE siRNAs. a GFP positive area represented where the AAVs was injected. b-d Double immunofluorescence for GFP and GFAP. Note that apoE siRNAs were expressed in GFAP positive astrocytes (arrowheads).

\section{Abbreviations}

AD: Alzheimer's disease; AAV: Adeno-associated virus; apoE: Apolipoprotein E; APP: Amyloid precursor protein; AQP4: Aquaporin 4; A $\beta$ : Beta-amyloid; BACE1: $\beta$-site amyloid precursor protein-cleaving enzyme 1; CSF: Cerebral spinal fluid; dcLNs: Deep cervical lymph nodes; CTF- $\beta$ : $\beta$-C-Terminal fragment; GFAP: Glial fibrillary acidic protein; GS: Glutamine synthetase; Iba1: Ionized calcium binding adapter molecule 1; IDE: Insulin-degrading enzyme; ISF: Interstitial fluid; Lamp1: Lysosome-associated membrane glycoprotein 1; LRP1: Low-density lipoprotein receptor-related proteins 1; NEP: Neprilysin; PFA: Paraformaldehyde; PS1: Presenilin-1; WT: Wild type

\section{Acknowledgements}

Not applicable.

\section{Authors' contributions}

$W F, Y Z, Z W$, and $H X$ conducted the experiments. WF, YZ, and ZW carried out the data analysis. TW, JG, and MX designed the experiments. CM and MX wrote the manuscript. All authors read and approved the final manuscript.

\section{Funding}

This work was supported by grants from the National Natural Science Foundation of China (81671070 and 81772454).

\section{Availability of data and materials}

The datasets used and/or analyzed during the current study are available from the corresponding author on reasonable request.

\section{Ethics approval and consent to participate}

All procedures in this study were performed according to the protocol reviewed and approved by the Nanjing Medical University Animal Care and Use Committee.

\section{Consent for publication}

Not applicable.

\section{Competing interests}

The authors declare that they have no competing interests.

\section{Author details}

${ }^{1}$ Jiangsu Province Key Laboratory of Neurodegeneration, Center for Global Health, Nanjing Medical University, Nanjing, China. ${ }^{2}$ Brain Institute, The Affiliated Nanjing Brain Hospital of Nanjing Medical University, Nanjing, China. ${ }^{3}$ Department of Neurology, The First Affiliated Hospital of Nanjing Medical University, Nanjing, Jiangsu, China. ${ }^{4}$ Department of Physical Therapy, University of Kentucky Center of Excellence in Rural Health, Hazard, KY, USA.

Received: 18 December 2019 Accepted: 15 September 2020

Published online: 02 October 2020

\section{References}

1. De Strooper B, Karran E. The cellular phase of Alzheimer's disease. Cell. 2016; 164(4):603-15.

2. Selkoe DJ, Hardy J. The amyloid hypothesis of Alzheimer's disease at 25 years. EMBO Mol Med. 2016;8(6):595-608.

3. Zlokovic BV, Yamada S, Holtzman D, Ghiso J, Frangione B. Clearance of amyloid beta-peptide from brain: transport or metabolism? Nat Med. 2000; 6(7):718-9.

4. Tanzi RE, Moir RD, Wagner SL. Clearance of Alzheimer's Abeta peptide: the many roads to perdition. Neuron. 2004;43(5):605-8.

5. Mawuenyega KG, Sigurdson W, Ovod V, Munsell L, Kasten T, Morris JC, et al. Decreased clearance of CNS beta-amyloid in Alzheimer's disease. Science. 2010:330(6012):1774.

6. Tarasoff-Conway JM, Carare RO, Osorio RS, Glodzik L, Butler T, Fieremans E, et al. Clearance systems in the brain-implications for Alzheimer disease. Nat Rev Neurol. 2015;11(8):457-70.

7. Liu CC, Hu J, Zhao N, Wang J, Wang N, Cirrito JR, et al. Astrocytic LRP1 mediates brain $A \beta$ clearance and impacts amyloid deposition. J Neurosci. 2017;37(15):4023-31

8. Zuroff L, Daley D, Black KL, Koronyo-Hamaoui M. Clearance of cerebral AB in Alzheimer's disease: reassessing the role of microglia and monocytes. Cell Mol Life Sci. 2017;74(12):2167-201.

9. Iliff JJ, Wang M, Liao Y, Plogg BA, Peng W, Gundersen GA, et al. A paravascular pathway facilitates CSF flow through the brain parenchyma and the clearance of interstitial solutes, including amyloid $\beta$. Sci Transl Med. 2012:4(147):147ra111.

10. Iliff J, Lee H, Yu M, Feng T, Logan J, Nedergaard M, et al. Brain-wide pathway for waste clearance captured by contrast-enhanced MRI. J Clin Invest. 2013;123(3):1299-309.

11. Kress BT, Iliff JJ, Xia M, Wang M, Wei HS, Zeppenfeld D, et al. Impairment of paravascular clearance pathways in the aging brain. Ann Neurol. 2014;76(6): 845-61. 
12. Zeppenfeld DM, Simon M, Haswell JD, D'Abreo D, Murchison C, Quinn JF, et al. Association of perivascular localization of aquaporin-4 with cognition and Alzheimer disease in aging brains. JAMA Neurol. 2017;74(1):91-9.

13. Mestre H, Hablitz LM, Xavier AL, Feng W, Zou W, Pu T, et al. Aquaporin-4dependent glymphatic solute transport in the rodent brain. Elife. 2018;7: e40070.

14. Hadjihambi A, Harrison IF, Costas-Rodríguez M, Vanhaecke F, Arias N, Gallego-Durán R, et al. Impaired brain glymphatic flow in experimental hepatic encephalopathy. J Hepatol. 2019;70(1):40-9.

15. Zhang R, Liu Y, Chen Y, Li Q, Marshall C, Wu T, et al. Aquaporin 4 deletion exacerbates brain impairments in a mouse model of chronic sleep disruption. CNS Neurosci Ther. 2020;26(2):228-39.

16. Nielsen S, Nagelhus EA, Amiry-Moghaddam M, Bourque C, Agre P, Ottersen OP. Specialized membrane domains for water transport in glial cells: highresolution immunogold cytochemistry of aquaporin-4 in rat brain. J Neurosci. 1997;17(1):171-80.

17. Peng W, Achariyar TM, Li B, Liao Y, Mestre H, Hitomi E, et al. Suppression of glymphatic fluid transport in a mouse model of Alzheimer's disease. Neurobiol Dis. 2016;93:215-25.

18. Niff JJ, Chen MJ, Plog BA, Zeppenfeld DM, Soltero M, Yang L, et al. Impairment of glymphatic pathway function promotes tau pathology after traumatic brain injury. J Neurosci. 2014;34(49):16180-93.

19. Xu Z, Xiao N, Chen Y, Huang H, Marshall C, Gao J, et al. Deletion of aquaporin-4 in APP/PS1 mice exacerbates brain A $\beta$ accumulation and memory deficits. Mol Neurodegener. 2015;10:58.

20. Fan Y, Zhang J, Sun XL, Gao L, Zeng XN, Ding JH, et al. Sex- and region specific alterations of basal amino acid and monoamine metabolism in the brain of aquaporin-4 knockout mice. J Neurosci Res. 2005;82(4):458-64.

21. Han X, Li Q, Lan X, El-Mufti L, Ren H, Wang J. Microglial depletion with clodronate liposomes increases proinflammatory cytokine levels, induces astrocyte activation, and damages blood vessel integrity. Mol Neurobiol. 2019;56(9):6184-96.

22. Tanaka Y, Chambers JK, Matsuwaki T, Yamanouchi K, Nishihara M. Possible involvement of lysosomal dysfunction in pathological changes of the brain in aged progranulin-deficient mice. Acta Neuropathol Commun. 2014;2:78.

23. Qiu WQ, Walsh DM, Ye $Z$, et al. Insulin-degrading enzyme regulates extracellular levels of amyloid beta-protein by degradation. J Biol Chem. 1998:273(49):32730-8.

24. Unger JW. Glial reaction in aging and Alzheimer's disease. Microsc Res Tech. 1998:43(1):24-8.

25. Kaur D, Sharma V, Deshmukh R. Activation of microglia and astrocytes: a roadway to neuroinflammation and Alzheimer's disease. Inflammopharmacology. 2019;27(4):663-77.

26. Kohl A, Dehghani F, Korf HW, Hailer NP. The bisphosphonate clodronate depletes microglial cells in excitotoxically injured organotypic hippocampal slice cultures. Exp Neurol. 2003;181(1):1-11.

27. Kumamaru H, Saiwai H, Kobayakawa K, Kubota K, van Rooijen N, Inoue K, et al. Liposomal clodronate selectively eliminates microglia from primary astrocyte cultures. J Neuroinflammation. 2012;9:116.

28. Kanekiyo T, Xu H, Bu G. ApoE and A in Alzheimer's disease: accidental encounters or partners? Neuron. 2014;81(4):740-54.

29. Achariyar TM, Li B, Peng W, Verghese PB, Shi Y, McConnell E, et al. Glymphatic distribution of CSF-derived apoE into brain is isoform specific and suppressed during sleep deprivation. Mol Neurodegener. 2016;11(1):74.

30. Harris FM, Tesseur I, Brecht WJ, Xu Q, Mullendorff K, Chang S, et al. Astroglial regulation of apolipoprotein $\mathrm{E}$ expression in neuronal cells. Implications for Alzheimer's disease. J Biol Chem. 2004;279(5):3862-8.

31. Yamazaki Y, Zhao N, Caulfield TR, Liu CC, Bu G. Apolipoprotein E and Alzheimer disease: pathobiology and targeting strategies. Nat Rev Neurol. 2019;15(9):501-18.

32. Cedazo-Mínguez A, Wiehager B, Winblad B, Hüttinger M, Cowburn RF. Effects of apolipoprotein $E$ (apoE) isoforms, beta-amyloid (Abeta) and apoE/ Abeta complexes on protein kinase C-alpha (PKC-alpha) translocation and amyloid precursor protein (APP) processing in human SH-SY5Y neuroblastoma cells and fibroblasts. Neurochem Int. 2001;38(7):615-25.

33. Tai LM, Bilousova T, Jungbauer L, Roeske SK, Youmans KL, Yu C, et al. Levels of soluble apolipoprotein E/amyloid- $\beta$ (A $A$ ) complex are reduced and oligomeric A $\beta$ increased with APOE4 and Alzheimer disease in a transgenic mouse model and human samples. J Biol Chem. 2013;288(8):5914-26.

34. Jankowsky JL, Slunt HH, Ratovitski T, Jenkins NA, Copeland NG, Borchelt DR. Co-expression of multiple transgenes in mouse CNS: a comparison of strategies. Biomol Eng. 2001;17(6):157-65.
35. Bilkei-Gorzo A. Genetic mouse models of brain ageing and Alzheimer's disease. Pharmacol Ther. 2014;142(2):244-57.

36. Trinchese F, Liu S, Battaglia F, Walter S, Mathews PM, Arancio O. Progressive age-related development of Alzheimer-like pathology in APP/PS1 mice. Ann Neurol. 2004;55(6):801-14.

37. Van Groen T, Kiliaan AJ, Kadish I. Deposition of mouse amyloid beta in human APP/PS1 double and single AD model transgenic mice. Neurobiol Dis. 2006;23(3):653-62.

38. Taoka T, Masutani Y, Kawai H, Nakane T, Matsuoka K, Yasuno F, et al. Evaluation of glymphatic system activity with the diffusion MR technique: diffusion tensor image analysis along the perivascular space (DTI-ALPS) in Alzheimer's disease cases. Jpn J Radiol. 2017;35(4):172-8.

39. Smith AJ, Yao X, Dix JA, Jin BJ, Verkman AS. Test of the 'glymphatic' hypothesis demonstrates diffusive and aquaporin-4-independent solute transport in rodent brain parenchyma. Elife. 2017;6:e27679.

40. Smith AJ, Verkman AS. The "glymphatic" mechanism for solute clearance in Alzheimer's disease: game changer or unproven speculation? FASEB J. 2018; 32(2):543-51.

41. Gyure KA, Durham R, Stewart WF, Smialek JE, Troncoso JC. Intraneuronal abeta-amyloid precedes development of amyloid plaques in Down syndrome. Arch Pathol Lab Med. 2001;125(4):489-92.

42. Gouras GK, Almeida CG, Takahashi RH. Intraneuronal Abeta accumulation and origin of plaques in Alzheimer's disease. Neurobiol Aging. 2005;26(9): 1235-44.

43. Oakley H, Cole SL, Logan S, Maus E, Shao P, Craft J, et al. Intraneuronal betaamyloid aggregates, neurodegeneration, and neuron loss in transgenic mice with five familial Alzheimer's disease mutations: potential factors in amyloid plaque formation. J Neurosci. 2006;26(40):10129-40.

44. Aspelund A, Antila S, Proulx ST, Karlsen TV, Karaman S, Detmar M, et al. A dural lymphatic vascular system that drains brain interstitial fluid and macromolecules. J Exp Med. 2015;212(7):991-9.

45. Louveau A, Smirnov I, Keyes TJ, Eccles JD, Rouhani SJ, Peske JD, et al. Structural and functional features of central nervous system lymphatic vessels. Nature. 2015;523(7560):337-41.

46. Da Mesquita S, Louveau A, Vaccari A, Smirnov I, Cornelison RC, Kingsmore $\mathrm{KM}$, et al. Functional aspects of meningeal lymphatics in ageing and Alzheimer's disease. Nature. 2018;560(7717):185-91.

47. Wang L, Zhang Y, Zhao Y, Marshall C, Wu T, Xiao M. Deep cervical lymph node ligation aggravates AD-like pathology of APP/PS1 mice. Brain Pathol. 2019;29(2):176-92

48. Yang W, Wu Q, Yuan C, Gao J, Xiao M, Gu M, et al. Aquaporin-4 mediates astrocyte response to $\beta$-amyloid. Mol Cell Neurosci. 2012;49(4):406-14.

49. Smith AJ, Duan T, Verkman AS. Aquaporin-4 reduces neuropathology in a mouse model of Alzheimer's disease by remodeling peri-plaque astrocyte structure. Acta Neuropathol Commun. 2019;7(1):74.

50. Fu Y, Zhao J, Atagi Y, Nielsen HM, Liu CC, Zheng H, et al. Apolipoprotein E lipoprotein particles inhibit amyloid- $\beta$ uptake through cell surface heparan sulphate proteoglycan. Mol Neurodegener. 2016;11(1):37.

51. Tachibana M, Holm ML, Liu CC, Shinohara M, Aikawa T, Oue H, et al. APOE4mediated amyloid- $\beta$ pathology depends on its neuronal receptor LRP1. J Clin Invest. 2019;129(3):1272-7.

52. Bales KR, Verina T, Dodel RC, Du Y, Altstiel L, Bender M, et al. Lack of apolipoprotein E dramatically reduces amyloid beta-peptide deposition. Nat Genet. 1997;17(3):263-4.

53. Kim J, Eltorai AE, Jiang H, Liao F, Verghese PB, Kim J, et al. Anti-apoE immunotherapy inhibits amyloid accumulation in a transgenic mouse model of AB amyloidosis. J Exp Med. 2012;209(12):2149-56.

54. Fryer JD, Taylor JW, DeMattos RB, Bales KR, Paul SM, Parsadanian M, et al. Apolipoprotein E markedly facilitates age-dependent cerebral amyloid angiopathy and spontaneous hemorrhage in amyloid precursor protein transgenic mice. J Neurosci. 2003;23(21):7889-96.

55. Kuszczyk MA, Sanchez S, Pankiewicz J, Kim J, Duszczyk M, Guridi M, et al. Blocking the interaction between apolipoprotein $E$ and $A \beta$ reduces intraneuronal accumulation of $A \beta$ and inhibits synaptic degeneration. Am J Pathol. 2013;182(5):1750-68.

56. Kamboh Ml. Apolipoprotein E polymorphism and susceptibility to Alzheimer's disease. Hum Biol. 1995;67(2):195-215.

57. Michaelson DM. APOE $\varepsilon 4$ : the most prevalent yet understudied risk factor for Alzheimer's disease. Alzheimers Dement. 2014;10(6):861-8.

58. Pankiewicz JE, Guridi M, Kim J, Asuni AA, Sanchez S, Sullivan PM, et al. Blocking the apoE/A interaction ameliorates AB-related pathology in APOE 
$\varepsilon 2$ and $\varepsilon 4$ targeted replacement Alzheimer model mice. Acta Neuropathol Commun. 2014:2:75

59. Huang YA, Zhou B, Wernig M, Südhof TC. ApoE2, ApoE3, and ApoE4 differentially stimulate APP transcription and AB secretion. Cell. 2017;168(3): 427-41 e21.

60. Wadhwani AR, Affaneh A, Van Gulden S, Kessler JA. Neuronal apolipoprotein E4 increases cell death and phosphorylated tau release in Alzheimer disease. Ann Neurol. 2019;85(5):726-39.

61. Shi Y, Yamada K, Liddelow SA, Smith ST, Zhao L, Luo W, et al. ApoE4 markedly exacerbates tau-mediated neurodegeneration in a mouse model of tauopathy. Nature. 2017;549(7673):523-7.

62. Farmer BC, Kluemper J, Johnson LA. Apolipoprotein E4 alters astrocyte fatty acid metabolism and lipid droplet formation. Cells. 2019;8(2):182.

63. Shinohara M, Sato N. The roles of Apolipoprotein E, lipids, and glucose in the pathogenesis of Alzheimer's disease. Adv Exp Med Biol. 2019;1128:85-101.

\section{Publisher's Note}

Springer Nature remains neutral with regard to jurisdictional claims in published maps and institutional affiliations.

Ready to submit your research? Choose BMC and benefit from:

- fast, convenient online submission

- thorough peer review by experienced researchers in your field

- rapid publication on acceptance

- support for research data, including large and complex data types

- gold Open Access which fosters wider collaboration and increased citations

- maximum visibility for your research: over $100 \mathrm{M}$ website views per year

At BMC, research is always in progress.

Learn more biomedcentral.com/submissions 